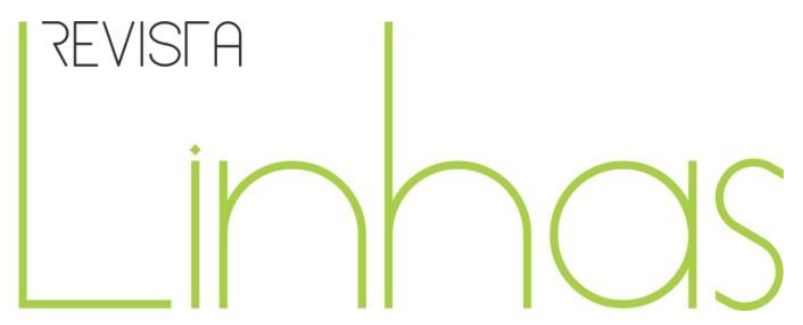

\title{
Políticas para o ensino médio: a criação do currículo no contexto escolar ${ }^{1}$
}

\begin{abstract}
Resumo
Neste artigo, apresentamos pesquisa realizada com docentes de duas escolas públicas de ensino médio, no Estado do Ceará, sobre os sentidos atribuídos à qualidade na educação a partir das ações do Programa Ensino Médio Inovador (ProEMI). Utilizamos como operador teórico o ciclo de políticas de Ball e Bowe (1998), apresentado e discutido a partir dos referenciais de Lopes (2006), Lopes e Macedo (2011), Ball e Mainardes (2011) e Mainardes (2006). Entendemos que as políticas educacionais são produções de significações curriculares desenvolvidas em múltiplos contextos, portanto, rompemos com a polarização dicotômica entre política e prática, buscando superar a compreensão da escola como local somente de resistência ou de implementação da política. Dessa maneira, os sentidos de qualidade constituídos, em última instância, pelos documentos do MEC, mesmo que aceitos pela escola, são reelaborados, traduzidos e ressignificados a partir da cultura escolar, tendo acepções diferentes em cada realidade, visto que são resultados de embates e disputas que envolvem múltiplos interesses da escola, da docência, da comunidade, dos órgãos diretivos, entre outros. As ressignificações efetivadas nas escolas, portanto, se diferenciam de acordo com o grau de reconhecimento, com a credibilidade da instituição e de sua relação com a comunidade escolar, com os órgãos diretivos do estado e com sua própria história.
\end{abstract}

Palavras-chave: Sentidos de qualidade; Tradução de políticas; Contexto da prática; Políticas educacionais.

\section{Jean Mac Cole Tavares Santos}

Professor na Faculdade de

Educação da Universidade do

Estado do Rio Grande do Norte UERN. Doutor em Educação pela Universidade Federal da Paraíba - UFPB - Brasil maccolle@hotmail.com

\section{Para citar este artigo:}

SANTOS, Jean Mac Cole Tavares. Políticas para o ensino médio: a criação do currículo no contexto escolar. Revista Linhas. Florianópolis, v. 17, n. 33, p. 261-283, jan./abr. 2016.

\section{DOI: $10.5965 / 1984723817332016261$}

http://dx.doi.org/10.5965/1984723817332016261

\footnotetext{
${ }^{1}$ CNPq (Bolsas de pós-doutorado - PDJ e Edital Universal 2012).
} 


\title{
Policies for secondary education: the creation of the curriculum in the school context
}

\begin{abstract}
This article presents research conducted with teachers from two public high schools in the state of Ceará about the meaning attributed to quality education from the actions of the Eastern Innovative Education Program (ProEMI). Used as a theoretical operator, the policy cycle of Ball and Bowe (1998), as presented and discussed, from the benchmarks Lopes (2006), Lopes and Macedo (2011), Ball and Mainardes (2011) and Mainardes (2006). We believe that educational policies are developed productions curricular meanings in multiple contexts. Therefore broke with the dichotomous polarization between politics and practice, seeking to overcome the understanding of school as a place only of resistance or implementing policy. Thus, the meanings of quality made, ultimately, by the MEC documents, even if accepted by the school, are reworked, translated, reinterpreted from the school culture, having different meanings in each reality, as are results of conflicts and disputes involving multiple interests of the school, the teaching, the community, governing bodies, among others. Resignifications effect in schools therefore differ according to the degree of recognition, the credibility of the institution and its relationship with the school community, with the governing bodies of the state and its own history.
\end{abstract}

Keywords: Quality in education; Translation of policy; Practice context; Educational policies. 
Apresentamos, neste artigo, resultados de pesquisa realizada com docentes de duas escolas públicas de ensino médio sobre os sentidos atribuídos à qualidade na educação a partir das atividades e projetos desenvolvidos nessas instituições. Interessanos perceber como os docentes respondem às exigências e expectativas dos projetos oficiais, aqueles que as escolas tomam como parâmetros para realizarem suas políticas educativas, no que diz respeito ao conceito de qualidade no ensino. Tomamos como base para o estudo as propostas do MEC para fortalecer essa modalidade de ensino, pois entendemos que tais contribuições, ao que pese não serem as únicas, nem isentas de críticas, são as que mais influenciaram no cotidiano escolar nos últimos vinte anos (SANTOS, 2007), estando, em tese, sempre voltadas para a melhoria da educação (CANDAU, 2002). Apesar de nossa investigação envolver, de forma geral, as atividades docentes, centramos nosso interesse nas ações desenvolvidas no Programa Ensino Médio Inovador (ProEMI), visando, assim, manter uma referência em ações desenvolvidas nas escolas pelos docentes, sendo possível, então, realizar uma reflexão mais balizada.

Utilizamos como operador teórico o ciclo de políticas de Ball e Bowe (1998), apresentado e discutido a partir dos referenciais de Lopes (2006), Lopes e Macedo (2011), Ball e Mainardes (2011) e Mainardes (2006). Logo, entendemos que as políticas educacionais são produções de significações curriculares desenvolvidas em múltiplos contextos. Essa visão rompe, portanto, com a polarização dicotômica entre política e prática, buscando superar a compreensão da escola como local somente de resistência ou de implementação da política. Dessa maneira, os sentidos de qualidade, em última instância, constituídos pelos documentos do MEC, mesmo que aceitos pela escola, são reelaborados, traduzidos e ressignificados a partir do contexto (SANTOS e OLIVEIRA, 2013) e da cultura escolar (BALL, 1994), tendo acepções diferentes em cada realidade. Essa diversidade de definições é, pois, resultado de embates e disputas que envolvem múltiplos interesses da escola, da docência, da comunidade, dos órgãos diretivos, entre outros. Por conseguinte, as ressignificações efetivadas nas escolas se diferenciam de acordo com o grau de reconhecimento, com a credibilidade da instituição e de sua relação com a comunidade escolar, com os órgãos diretivos do estado e com sua própria 
história. O know-how da escola é, destarte, elemento definidor dos sentidos de qualidade.

As duas escolas pesquisadas, diferentes entre si em vários aspectos, como veremos mais adiante, foram escolhidas por terem em comum o fato de atuarem no ensino médio desde o processo inicial de expansão dessa modalidade. De cada escola, entrevistamos dois docentes e um membro do núcleo gestor, totalizando seis depoimentos. Escolhemos para depoentes professores atuantes durante o período de nosso estudo, não importando a função desenvolvida em todos os vinte anos de existência das instituições investigadas, haja vista a alta rotatividade de funções dentro das escolas e de docentes entre elas (SANTOS, 2007). Posto isso, o fato de o professor permanecer na mesma instituição viabiliza contribuição para este estudo.

\section{Situando a pesquisa}

A partir de meados dos anos noventa, pudemos verificar um processo de expansão do ensino médio que, pela primeira vez na história do Brasil, atenderia parcela considerável da população jovem. Com décadas de atraso, se compararmos com alguns países europeus e com os Estados Unidos, várias inciativas governamentais referenciadas pela Lei de Diretrizes e Bases da Educação Nacional (LDB), Lei 9394/96, foram anunciadas, apontando que a educação secundária tomaria novos rumos, seria revolucionada e faria, cada vez mais, parte da vida de jovens e adolescentes. As propostas para o ensino médio refletidas nessa pesquisa, nas ações do Ministério da Educação (MEC), traçavam um discurso sobre qualidade educacional, tendo como referências aspectos flutuantes entre a atenção às avaliações internas e externas e o atendimento de seus objetivos formativos. Não obstante, alguma ideia de qualidade sempre fez parte das bandeiras políticas que justificariam as intervenções no ensino médio. Entretanto, os sentidos construídos e a ênfase em um dos aspectos dessa qualidade variam de acordo com os pressupostos defendidos pela reforma e pela disputa política dos significados do conceito de qualidade (LOPES, 2006).

No início da expansão, durante o primeiro governo de Fernando Henrique Cardoso, o ensino médio foi propagandeado como para a vida e, além da LDB, tinha como 
referenciais as Diretrizes Curriculares Nacionais para o Ensino Médio (DCNEM), os Parâmetros Curriculares Nacionais do Ensino Médio (PCNEM) e o Decreto 2208/97. Grosso modo, essa proposta para o ensino médio centrava-se na formação geral, tecnológica e propedêutica, trazendo a ideia de um "Novo Ensino Médio". O foco da reforma era adaptar o ensino às novas determinações do mundo do trabalho, pautado nas transformações técnicas e científicas, na revolução tecnológica e na sociedade da informação. Como lema, tratou-se de enunciar que "o ensino médio, agora, é para a vida", aproximando a sala de aula dos elementos cotidianos da vida do aluno e dos interesses imediatos da sociedade (BRASIL, 1999).

Segundo os documentos do Novo Ensino Médio, junto com o caráter imposto pela terminalidade da Educação Básica, a LDB estabelece um princípio de formação geral, o que exige a unificação entre formação tecnológica (e não, especificamente, técnica) e humana, sendo necessária ainda a vinculação da educação com o mundo do trabalho e a prática social. Tais passos consolidariam a preparação para o exercício da cidadania e propiciariam qualificação básica para o trabalho (BRASIL, 1999).

Nos termos da LDB, vemos, então, a qualidade associada à cidadania e formação para o trabalho, planejamento que perdurou durante os oitos anos do governo FHC. Consequentemente, avaliar a qualidade é, também, verificar os índices de empregabilidade, buscando perceber se a educação "cumpre" sua função de propiciar melhores condições de emprego e renda aos jovens brasileiros (SANTOS, 2007). Concomitante a esse pensamento, foi igualmente forte o apelo referendando a qualidade relacionada às avaliações de desempenho em exames nacionais e internacionais e aos índices gerais de aprovação, reprovação e abandono escolar copilados pelo Censo Escolar. Por suposto, a análise desses referenciais mantinha decisiva influência no discurso de qualidade, ou não, da educação (FREITAS, 2004).

Já durante os dois mandatos presidenciais de Luís Inácio Lula da Silva, o ensino médio ganhou uma proposta integrada. Apesar de, nos primeiros anos, apenas administrar a herança de Fernando Henrique, o governo Lula revogou o decreto 2208/97, mostrando-se sensível ao apelo de uma parcela significativa dos educadores, muitos deles da base de apoio político do Partido dos Trabalhadores (PT). A partir desse momento, a lei passa a sinalizar para o ensino médio integrado, de acordo com o Decreto 5154/04, o 
que ocasionou uma verdadeira reviravolta na política educacional brasileira. Com isso, o Ministério da Educação propôs uma guinada na relação entre a formação técnica e o ensino médio, enquanto o MEC sugeriu uma proposta de ensino médio integrado ao profissionalizante, pensando na articulação da formação profissional em nível médio com o próprio ensino médio. Assim, torna-se sem efeito legal o Decreto 2208/97, que reforçava a visão dual na formulação e condução das políticas de educação básica e da educação profissional e tecnológica do Ministério da Educação. Logo, o Decreto 5154/2004 foi um marco importante na medida em que revogou a norma que pretendia a separação entre o ensino médio e a educação profissional técnica de nível médio. Outrossim, delegou a decisão das formas de articulação entre a educação profissional (integrada, concomitante e subsequente) e o ensino médio para a as redes e instituições escolares.

A integração do ensino médio passa, pois, a ser referência, medindo a qualidade do aprendizado por uma suposta relação entre teoria e prática. A formação cidadã e a possibilidade de incluir o jovem egresso no mundo do trabalho, além de objetivos, tornam-se marcas para a avaliação da qualidade de educação, a qual convive com os fins da proposta para o ensino médio, formação cidadã e inclusão no mundo do trabalho e com avaliações de desempenho em âmbito nacional.

No final do segundo governo de Lula e no início da presidência de Dilma Rousseff, começa a tomar forma a atual proposta do MEC, denominada Ensino Médio Inovador. $\mathrm{O}$ Programa Ensino Médio Inovador (ProEMI) pretende induzir o redesenho dos currículos do Ensino Médio, compreendendo que as ações “propostas inicialmente vão sendo incorporadas ao currículo, ampliando o tempo na escola e a diversidade de práticas pedagógicas, atendendo às necessidades e expectativas dos estudantes do ensino médio" (BRASIL, 2013, p. 9).

Conforme o Documento, o objetivo dessa modificação curricular é garantir o acesso à educação de qualidade, atendendo "às necessidades e expectativas dos jovens brasileiros", sendo que, para atingir tal escopo, é necessário compreender os sujeitos e as juventudes presentes no Ensino Médio brasileiro e seus direitos à aprendizagem e ao desenvolvimento integral. Porém, o ProEMI mantém a histórica preocupação com os indicadores da educação, relacionando-os, sempre que possível, ao desempenho 
(aprovação, reprovação, evasão, distorção idade-série, percentual de alunos matriculados, resultado do ENEM, resultado do IDEB, resultado do PISA). Por consequência, busca atender aos quesitos quantitativos da avaliação, deixando subentendido o que entende por qualidade, isto é, subsumir o objetivo às "necessidades e expectativas" dos alunos do ensino médio. Diferente de outros momentos, quando a “preparação para o trabalho", a "formação cidadã”, a "“inclusão na era digital” ou a “incorporação ao mundo produtivo" tinham assento nos fins da educação, "necessidades e expectativas", nessa conjuntura, abrem ainda mais possibilidade de construir diferentes parâmetros para dialogar com a ideia de qualidade na educação.

No mais, nas últimas duas décadas, esses discursos sobre a qualidade, difusos e sem clareza de sentidos, têm rondado a escola de ensino médio. Sob essa ótica, entendemos que as escolas, a partir de sua dinâmica própria, preencheram os sentidos apontados nos referenciais oficiais relativos a esse contexto, dando um fechamento, mesmo que provisório, ao que desejavam construir como fins de projeto educacional. Isso explica, em parte, a continuidade de alguns traços básicos da qualidade (formação para o trabalho e para a cidadania em propostas antagônicas, por exemplo), forjada pela lógica da escola. O que investigamos, portanto, é o comportamento das instituições educacionais quando os referenciais ficam cada vez mais abertos, incluindo necessidades e expectativas, num processo que demanda continuidades e rupturas (e não simplesmente do ponto de vista da política partidária). Enfim, almejamos compreender como a escola lida com a abertura dos fins da educação para as necessidades e expectativas, num contexto, de décadas, que envolve fortemente a formação para o trabalho e para a cidadania e que ainda precisa responder às avaliações quantitativas de âmbito nacional, como o ENEM e o IDEB.

\section{Política como construção em diferentes ciclos}

Tomando como referência as atividades realizadas na escola, desde as ressignificações das políticas para o Ensino Médio Inovador, é desejo nosso apreender, ainda, como os docentes percebem/constroem, contextualmente, a qualidade da educação. Essa ação tem como base teórica os apontamentos de Ball (1994, 1998), 
Mainardes (2006) e Lopes (2006), os quais nos conduzem ao entendimento de que investigar as ressignificações das políticas na escola é examinar conexões, relações, apropriações, traduções e interdependências, vislumbrando que políticas são processos construídos contextualmente. Desse modo, as práticas políticas são específicas e contextualizadas, sendo efetivadas de maneiras diversificadas, a partir da dinâmica de cada escola. Pensando assim, atores envolvidos na (re)elaboração das políticas, entre eles professores, gestores, dirigentes e técnicos das secretárias e do MEC, influenciam os rumos e a dinâmica de cada ação. Além disso, a situação da escola, seu reconhecimento e posição na comunidade, seu poder de enfrentamento e de mediação na relação com os órgãos - que pode ser resultado de vários processos históricos e sociais, algo que Ball resumiu como sendo a cultura escolar - são também fatores a serem considerados no entendimento de como as políticas são mediadas.

Com a perspectiva acima, buscamos nos afastar de concepções que pensam a política como factível de implementação na escola, após ser formulada em alguma instância estatal. Contudo, não desconsideramos o papel do Estado na elaboração de políticas, reconhecendo, inclusive, sua força de indução de práticas nas escolas. Ponderamos, pois, sobre a existência de várias circunstâncias que corroboram para as políticas educacionais, crendo que as propostas estatais são construídas e (re)elaboradas em vários contextos, os quais, na prática docente, são ressignificados pelos sujeitos que atuam na escola, a partir de seus saberes/poderes, concepções e apropriação do mundo. Por ressignificação entendemos não os novos sentidos que professores e gestores poderiam dar a partir de um sentido original da política, mas os próprios sentidos construídos e reconstruídos na/pela escola numa relação de compreensão e tradução das propostas, configurada em projetos híbridos (BALL, 1994). Quanto a esse hibridismo, é concebido como "a mistura de lógicas globais, locais e distantes, sempre recontextualizadas" na prática docente, influenciados pelo contexto escolar (LOPES, 2005, p. 56).

A ressignificação, portanto, não acontece simplesmente pela ação de seus intérpretes (professores e gestores) na escola. Como mostra Ball (1998), não se trata de colocar políticas em prática, pois este é um processo criativo, sofisticado e complexo que também se localiza sempre em um determinado contexto e lugar. Falar de contexto, pela 
força do uso desse termo nas perspectivas estruturalistas (principalmente pela esquerda marxista althusseriana), remete à ideia de relação direta com os aparelhos ideológicos, com a base econômica e política e, em maior grau, com uma arrebatadora força da história e da cultura. Contrariamente, definimos contexto como os movimentos realizados pela escola, (re)construindo sentidos globais e locais, em várias direções e, principalmente, em relação aos órgãos governamentais, à comunidade escolar e à própria escola. É por esse viés que focalizamos, de forma geral, os sentidos consolidados na escola para qualidade da educação, a qual, de alguma maneira, perpassa as ações desenvolvidas pelos docentes, e as relações de ressignificação e tradução possíveis no seu entrecruzamento com o documento ProEMI.

Para dar conta dessa interpretação, utilizamos a perspectiva do "ciclo contínuo de políticas", de Stephen Ball e Richard Bowe, apresentado e discutido por Lopes (2006), Lopes e Macedo (2011), Ball e Mainardes (2011) e Mainardes (2006). De acordo com esse ciclo, as políticas educacionais não são, de forma estanque, oriundas dos governos e da estrutura estatal, pelo contrário, partem de vários contextos. Assim, tentamos nos afastar das análises estadocêntricas que desejam a política educacional como direcionada pelo Estado e implementada pela escola, deixando quase nenhuma perspectiva de reelaboração pelos sujeitos, a não ser resistir ou implementar o projeto imposto.

Na abordagem do "ciclo contínuo de políticas", Ball $(1998,2011)$ e Ball e Bowe (1998) realçam a complexidade inerente à análise da política educacional, "enfatizando os processos micropolíticos e a ação dos profissionais que lidam com as políticas no nível local e indica a necessidade de se articularem os processos macro e micro na análise de políticas educacionais" (MAINARDES, 2006, p. 48). O ciclo contínuo de Stephen Ball e Richard Bowe é constituído, inicialmente, por três contextos, a saber: o de influência, o da produção de textos e o da prática. Posteriormente, outros dois são apresentados: o contexto dos resultados (efeitos) e o da estratégia política. Vale ressaltar que todos os contextos estão inter-relacionados, não havendo nenhuma dimensão linear ou sequencial obrigatória entre eles.

Explicando de maneira didática cada um desses contextos, podemos dizer que é no contexto de influência que as políticas públicas são, também, significadas e os discursos políticos construídos de forma mais sistemática. 
É nesse contexto que grupos de interesse disputam para influenciar a definição das finalidades sociais da educação e do que significa ser educado. Atuam nesse contexto as redes sociais dentro e em torno de partidos políticos, do governo e do processo legislativo. É também nesse contexto que os conceitos adquirem legitimidade e formam um discurso de base para a política. $O$ discurso em formação algumas vezes recebe apoio e outras vezes é desafiado por princípios e argumentos mais amplos que estão exercendo influência nas arenas públicas de ação, particularmente pelos meios de comunicação social. Além disso, há um conjunto de arenas públicas mais formais, tais como comissões e grupos representativos, que podem ser lugares de articulação de influência. (MAINARDES, 2006, p. 52)

O contexto de influência, então, é caracterizado por disputas na construção dos discursos que irão definir os princípios gerais da política educacional. Vários grupos de interesse pleiteiam significações do mundo para influenciar os sentidos das finalidades sociais das políticas de educação. Aqui, por conseguinte, os conceitos adquirem legitimidade e formam um discurso de base para a política. Dizer isso, insistimos, é diferente de afirmar que as ideias nascem nesse contexto para, a partir dele, serem irradiadas aos outros contextos (mesmo que passando pelos crivos e disputas em cada um dos outros contextos).

Já no contexto da produção de textos, acontece a caracterização dos textos das políticas educacionais, os quais envolvem, de forma geral, técnicos dos governos, parlamentares, especialistas em diversas áreas, assessores parlamentares, consultores de organizações não governamentais e pesquisadores de várias instituições.

Os textos políticos, portanto, representam a política. Essas representações podem tomar várias formas: textos legais oficiais e textos políticos, comentários formais ou informais sobre os textos oficiais, pronunciamentos oficiais, vídeos, etc. Tais textos não são, necessariamente, internamente coerentes e claros, e podem também ser contraditórios. (MAINARDES, 2006, p. 52)

Na produção de textos, os antagonismos e conflitos apresentados no contexto de influência circulam em disputas por hegemonias para representarem e representarem-se na escrita. Destarte, os textos são o resultado de disputas, acordos, encontros, alianças entre grupos que atuam em diferentes lugares, com diferentes concepções, almejando 
controlar as representações da política. Nesse contexto os textos políticos tomam forma escrita com a pretensão de atender ao interesse público geral.

Finalmente, o contexto da prática pode ser caracterizado pelas ações ocorridas nas escolas. Nele são realizadas:

\begin{abstract}
leituras dos textos das políticas e estes são reinterpretados e, assim, são produzidos novos discursos que perpassam os demais contextos, em uma circularidade contínua. Nesse sentido, devemos pensar a prática como parte da política, visto que sentidos da prática estão representados nas políticas de forma bastante imbricada, evidenciando a constante produção de políticas no contexto da prática, na medida em que ocorre uma troca constante entre propostas e práticas: os sentidos das propostas perpassam a prática, assim como os sentidos da prática perpassam as propostas. (BUSNARDO, 2009, p. 35)
\end{abstract}

Evidenciando, contingencialmente, que é esse contexto que nos interessa, entendemos que a escola não pode ser vista apenas como receptáculo de políticas pensadas longe de sua realidade, tendo a função somente de implementar, como vítima indefesa, tudo o que fora elaborado alhures. No contexto da prática, a política está sujeita à interpretação e recriação, pois ela produz efeitos e consequências que podem representar mudanças e transformações significativas na proposta política oficial. Como proposta, ao chegar às escolas, essa política é ressignificada, recontextualizada por hibridismo pelos profissionais da educação que ali atuam. O professor, em sua função docente, tem, por exemplo, a liberdade de recriá-la e reinventá-la. Como se pode ver, a referida política é "interpretada de diferentes formas, uma vez que experiências, valores e interesses são diversos" (MAINARDES, 2006, p. 53). Sendo parte do ciclo, os agentes mantêm intensa relação com sua construção, seja na ressignificação das propostas apresentadas e nas releituras e reinterpretações dos textos das políticas, seja nas trocas constantes entre os vários contextos.

Sob esse ponto de vista, o foco da análise de políticas deve incidir sobre a formação do discurso da política e sobre a interpretação ativa que os profissionais que atuam no contexto da prática fazem para relacionar os textos da política à prática. Como defendeu Mainardes (2006), cada um dos contextos apresentados por Ball e Bowe (1998) são constituídos de arenas, de lugares de discussão, de ambientes de disputas e de 
grupos de interesses que desejam influenciar as políticas. São, pois, ambientes que envolvem embates pela significação das políticas, certamente relacionando-as com sua compreensão de mundo e seus interesses nele.

\section{Qualidade na educação: construção de sentidos em vários contextos}

Com a compreensão de que as escolas são arenas de disputas de diversos projetos, onde convivem atores sociais que pensam e agem no mundo a partir de interesses diversos, nem sempre conscientes, inteligíveis e disciplinados, buscamos perceber os sentidos de qualidade na educação operados nesses espaços. Para isso, selecionamos duas escolas que estão desenvolvendo ações a partir do Projeto Ensino Médio Inovador, proposto pelo MEC, intentando relacionar as perspectivas de qualidade do ProEMI e as apresentadas pelos docentes atuantes nas instituições. É importante dizer que queremos construir essa relação sem desconsiderar outros sentidos de qualidade, muitos deles oriundos de outras propostas oficiais de reformas educacionais e que continuam circulando nas escolas, dialogando com aqueles (re)construídos pelos atores escolares.

Em suma, pesquisar sobre qualidade na educação exige perceber os híbridos sentidos de qualidade que permeiam o ambiente escolar, ação possível, em nossa compreensão, somente através da sua contextualização nos espaços de ensinoaprendizagem. Por isso, a seguir apresentamos as escolas e as falas dos entrevistados, intercalando as últimas com a discussão, no intuito de clarear nossa argumentação. Para preservar tanto as escolas como seus depoentes, optamos pelo anonimato das falas e do nome das instituições. Dessa forma, trataremos a primeira escola pelo codinome de Capital e a segunda, por sua vez, pelo codinome de Urbana. Já os entrevistados serão designados por números, ao passo que 1, 2 e 3 são referentes à escola Capital, enquanto 4, 5 e 6 pertencem à escola Urbana. Quanto à exposição de suas falas dentro do texto, não seguem uma sequência ordinária, sendo encaixadas aleatoriamente, de acordo com sua relevância para a discussão.

A escola Capital, reconhecida como uma das melhores escolas públicas do Estado do Ceará, está situada em um bairro central da cidade, recebendo alunos da periferia e da 
região metropolitana de Fortaleza. Tal reconhecimento pode ser percebido na intensiva divulgação de suas atividades em vários meios de comunicação, principalmente nos jornais impressos de grande circulação e nas redes sociais, além de um sítio próprio na rede mundial de computadores. Segundo membro do núcleo gestor (Entrevistado 2), a escola se esforça para manter o reconhecimento de seu desempenho e, por conseguinte, atrai a atenção das autoridades do Estado e dos meios de comunicação. Capital é manchete, de acordo com o depoente, devido às filas que se formam durante as matrículas, já que a procura é bem maior do que a disponibilidade de vagas. É destaque também nas matérias sobre o desempenho dos alunos das escolas públicas no Exame Nacional do Ensino Médio (ENEM) e na aprovação em outros processos de acesso ao ensino superior. Porém, o entrevistado faz questão de frisar que a escola não faz propaganda, apenas repassa as informações para os veículos de comunicação. Conforme seu pronunciamento:

Não há grande preocupação em buscar inserir informações nos jornais. Eles é que sempre nos procuram para pedir entrevistas, para saber informações sobre nossos alunos, sobre o [desempenho da escola no] ENEM, sobre as filas de matrículas no início de cada ano. É, ao contrário, a fama da escola que traz muita procura da mídia. Claro que isso gera também mais popularidade, mais fama, mais procura, porque afinal quem não quer ver seu filho estudando numa boa escola pública? (Entrevistado 2)

O reconhecimento da escola Capital, como se pode ver, acontece de maneira direta, sendo considerado "natural", fruto do seu desempenho. Nas palavras do entrevistado 1:

Não temos preocupação direta com a divulgação de nossos resultados. Temos preocupação em manter e ampliar as conquistas. São as conquistas que atraem mais interesse pela escola. (...) Os resultados geram uma [boa] repercussão na mídia; não é mídia que traz os resultados. Nós temos fama por causa dos resultados. Os resultados é que trazem a fama. 
Em uma busca rápida nas páginas dos dois principais jornais impressos do Estado, conseguimos localizar dezenas de matérias sobre a escola Capital. Os assuntos mais recorrentes são mesmo a respeito dos temas apresentados pelo gestor da escola (Entrevistado 2). Porém, vários outros temas estão entre as manchetes dos diários cearenses, entre eles: cursos de educação integrada; olimpíadas escolares; feira de ciências; participação da escola em eventos nacionais; reconhecimento recebido pelos professores da escola (incluindo aí os gestores); prêmios conquistados pelos alunos em concursos nacionais de matemática, de química e de história; e outras premiações dos discentes (inclusive em disputas esportivas). O prestígio da escola, a ideia de ser referência é, assim, uma marca que professores e gestores fazem questão de exaltar, e é através desse reconhecimento que a escola constrói os sentidos sobre si.

Em contrapartida, a escola Urbana, localizada em uma cidade de médio porte, no interior do Estado do Ceará, tendo sido a primeira escola de ensino médio da região e, por isso, principal polo educacional das cidades circunvizinhas, atualmente, disputa alunos e atenção com outras duas instituições de ensino médio na mesma cidade. Com uma estrutura física para 1200 (mil e duzentos) alunos, vem sofrendo com a diminuição gradativa da procura. A maior parte de seu quadro docente é de professores temporários, com carência maior nas áreas de Matemática, Física e Língua Estrangeira. Alguns relatos dão conta de que, em vários anos, não foi possível completar todas as aulas dessas disciplinas, resolvendo-se o problema com atividades complementares e outros arranjos feitos pela escola para não 'prejudicar' os alunos. Segundo seu gestor (Entrevistado 4), a conquista do ProEMI se deu pela mobilização da comunidade escolar e pelo reconhecimento histórico do papel da escola na formação de várias gerações. Nas suas palavras:

A partir da ideia, que veio da CREDE, mobilizamos a comunidade, fizemos reuniões, aprovamos um plano de ação e ficamos na expectativa de sermos escolhida. Sabíamos que só poderia ser uma escola nesse município. A nossa é a mais antiga, a mais reconhecida, a mais tradicional. Tinha que ser a nossa. A nossa história fez a diferença na hora da decisão. (Entrevistado 4) 
Podemos considerar, então, a descrição acima, como ativista, defendendo o legado histórico e enfatizando a necessidade da escola Urbana em resposta aos serviços prestados ao longo dos anos e gerações. Mesmo assim, a instituição precisa manter sua existência, reafirmando sua história, disputando espaços e mostrando a importância de suas ações para a cidade e para a região de que faz parte.

Receber a proposta do ProEMI, para essa escola, foi considerada uma vitória, haja vista as possibilidades de recursos oriundos do governo federal, via MEC, importantes para o desenvolvimento de suas atividades. Diferentemente da primeira escola citada, esta teve de mobilizar, fazer pressão, apresentando seus melhores argumentos para receber o "convite". Portanto, assim nos diz o entrevistado 4:

Os recursos eram bons. A proposta era excelente. Tínhamos que conseguir nosso espaço. Se a proposta veio para melhorar a qualidade do Ensino Médio, como a escola que foi pioneira no Ensino médio iria ficar de fora? Não podia, podia? Não podíamos ficar de fora, enfrentamos o desafio e fomos escolhidos. Nada contra os outros, mas tradição também é importante. Podemos até hoje estar passando por alguns problemas, mas sempre demos nossa contribuição para o município para o estado [...].

A medida da qualidade como um dos elementos tradicionais é marcante na fala do entrevistado. Segundo ele, não se pode pensar em qualidade da educação negando o passado, a história da cidade e a contribuição da escola para a formação de muitos líderes municipais de várias épocas. A tradição é, então, elemento definidor na fala do gestor, servindo como âncora para fortalecer e justificar as pretensões da escola.

Destarte, Capital e Urbana, cada uma com suas armas, construídas a partir de seu contexto, das condições existentes, das diversas disputas que foram consolidando suas culturas, tomam posição no quadro geral da política educacional, influenciando e sendo influenciadas pelos movimentos, enfrentando os desafios da qualidade como um dos elementos de fortalecimento de seus sentidos de si. Como discutem Ball e Bowe (1992), os atores escolares tomam posições em relação às políticas e aos interesses de órgãos da administração escolar de acordo com o (auto) reconhecimento de suas possibilidades. Assim, admitindo o conflito ou - para ficar com uma expressão utilizada por Ball, Maguire 
e Braun (2012) - as disputas entre os projetos a serem postos em prática - -, fica claro que o fortalecimento do nome da escola perante a comunidade, mantendo sua fama de instituição de qualidade, possibilita muitos enfrentamentos que, em outros casos, não seriam possíveis.

Caminhar, contudo, com as ideias de fortalecimento da escola atendendo os interesses da comunidade e oferecendo o que os alunos desejam, exige algumas conformações dos discursos dos depoentes. A exemplo, um docente da escola Capital apresenta uma fala que indica contradição. Senão vejamos:

Qualidade é mais do que somente aprovar quase duzentos alunos nos vestibulares da cidade, apesar de não podermos abrir mão disso, pela exigência da própria comunidade escolar. Qualidade é formar para a vida, pra ser cidadão crítico, como disse Paulo Freire, e não apenas aceitar tudo que vem de cima. Nesses dois pontos nossa escola está de parabéns. Cumpre com sobra o propósito da educação. Por isso não deixamos ninguém mexer com a gente. Nós decidimos o que é melhor, como fazer. Com muita democracia, com muita participação. (Entrevistado 3)

Mesmo reconhecendo que existe problema em aceitar alguns referenciais de qualidade impostos pelas políticas, a escola segue algumas diretrizes quantitativas, atendendo aos interesses comuns dessa política e da sociedade, pois entende que faz parte de como o mundo se realiza. É visível, então, o conflito entre uma perspectiva focada nos resultados, nas aprovações, e o desejo de formação mais geral, cuidando de aspectos que possibilitem a formação humanística, na perspectiva de formação cidadã.

Essa mesma ideia de formar para a cidadania está no discurso do gestor. Ele une duas preocupações básicas, já reveladas em outras vozes da escola, a saber: manter a autonomia da escola e desenvolver uma educação de qualidade que fuja do padrão quantitativo. Em seu pronunciamento, enfatiza o seguinte:

De nada adianta formar somente com conteúdos. O aluno precisa saber pensar, caminhar com suas próprias pernas, refletir sobre o mundo que vive e lutar para mudar. Passar no vestibular, ser reconhecido como uma 
escola que aprova muito é superimportante. Mas não é o fim da educação. Precisa investir na formação humana, na construção de consciências que possam exigir seus direitos. Escola de qualidade precisa unir os dois objetivos num só. Só assim somos respeitados. Só assim mantemos nossa autonomia, enfrentamos os autoritarismos do governo da SEDUC, desse povo que não sabe o que é uma sala de aula e vive exportando metodologias inovadoras, querendo que a gente imite o que deu certo ‘num sei onde’. (Entrevistado 2)

De fato, na homepage da escola Capital é possível encontrar várias ações que propõem o "desenvolvimento de habilidades gerais dos alunos", como apresentou o entrevistado 1. Atividades de estudos sobre meio ambiente, inclusão e diversidade, educação sexual e consciência negra são destaques apresentados pela escola. Entretanto, a chamada central da página é para os dados quantitativos de aprovação via vestibular, ENEM e PROUNI. Logo, verificamos que, tanto pelas falas, quanto pela representação no site, qualidade, para os funcionários da referida escola, passa pela quantificação, pelos resultados obtidos nos números de aprovação. Sendo assim, o que para nós, aparentemente, é contradição, para a escola é forma encontrada para construir seu sentido de qualidade, respondendo as exigências do "seu público", e, ao mesmo tempo, buscando fortalecer um discurso de superação do tecnicismo.

Para a escola Urbana, por sua vez, o raciocínio da qualidade como aprovação não encontra justificativa direta em suas atuações. Assim que a fala a seguir, por exemplo, apela para outras significações do que pode ser qualidade. Observemos:

Sei que há uma febre pelos resultados do ENEM. As escolas, principalmente as particulares, fazem questão de colocar placas mostrando seu desempenho, contando os alunos que passaram [...]. Mas eu duvido eles obterem aquele desempenho a partir dos alunos que nós temos, com as condições que nós temos. Nem tudo pode ser medido pelos resultados dos vestibulares, pelas aprovações [...], como muitos desejam. Qualidade pra mim não pode ser medida assim. Precisa ver que nem todo mundo pode pagar escola cara. As famílias não podem mandar os filhos para estudar fora [em Fortaleza]. Precisam dessa escola, com tudo que fazemos, com nossa história, fruto da vontade e de sonhos [...] de muita gente. (Entrevistado 5) 
Qualidade na educação, portanto, representa, na visão do depoente, a possibilidade de existir, numa realidade adversa, para atender a parcela da população que não pode (ou não quer) se deslocar para longe, para outra cidade. A medida aqui é a medida do possível, justificando os números insatisfatórios nas provas de desempenho e, ainda, referendando-se na realidade local.

Os entrevistados nessa escola insistem em fazer referência aos tempos áureos, quando a instituição era reconhecida pela grande contribuição para a cidade e para a região onde está localizada. Tempo em que ter o ensino médio, principalmente se fosse um curso técnico, contabilidade ou pedagógico, era fundamental ou, nas palavras do entrevistado 2, "suficiente para trabalhar, para assumir os empregos na prefeitura e nas escolas que precisam de professoras formadas". O ensino médio, então, "fazia sentido, pois bastava ter o diploma para o sujeito ser reconhecido, trazendo reconhecimento também para a escola" e para os professores que atuavam nela sem o risco, "sem as ameaças de fechar a escola, de mandarem a gente trabalhar em outra cidade, longe daqui”. Defender a escola e a qualidade do ensino a partir da realidade existente é, assim, condição para sua existência, para seu estabelecimento como local de trabalho, de suas memórias e, não menos importante, da tradição de ser importante, consequentemente contribuindo com o desenvolvimento do lugar onde está inserida. Esses são, portanto, interesses legítimos de pertencimento, nos quais a memória é um fenômeno social (HAWBACHS, 2006).

Tanto quanto a escola Capital, a Urbana apresenta suas contradições. Nesse sentido, a formação de qualidade para o público existente traz o dilema da busca pela aprovação para o vestibular, via ENEM, e para a inclusão no mundo do trabalho, por meio dos empregos precários existentes. Posto isso, os sentidos que a escola traz para qualidade são referendados no aluno, como exige o ProEMI, apresentando-se essa ideia como uma desculpa, uma falta, e não como a afirmação de que a escola está cumprindo com sua função. Por suposto, seu olhar condenatório para a outra realidade, a da outra escola que aprova, pode induzir o sentimento de vontade de aproximação com o que é vivido pela instituição adversa. Quer dizer, não há, na escola em discussão, convicção no seu trabalho, na sua definição de qualidade, há o sentimento de falta, revestido de “possível”. Mas, e quando o "impossível” acontece? Aí é tomado como exceção, como 
deslocamento da qualidade, isto é, segue-se o lema de que sai da escola, passa para o aluno. Já nos casos de aprovação, a proeza passa a ser do aluno, não da escola.

A opção de supervalorizar o aluno em detrimento da escola não faz sentido para a Capital. Sem ceder ao cálculo para medir sua qualidade, apontando a necessidade de unir a formação geral à técnica, de se preocupar com a consciência dos indivíduos e com a "soma de conhecimentos para os alunos enfrentarem a vida lá fora" (entrevistado 2), o depoimento abaixo consolida a visão da escola sobre a qualidade:

Qualidade é tudo que fazemos em prol de nosso aluno. Aula de qualidade é aula que o aluno aprende. Por isso que o projeto na escola dá certo. Não porque a SEDUC exige; não porque está no documento do [Ensino Médio] Inovador. Funciona porque buscamos adaptar à realidade do nosso aluno. Temos essa flexibilidade, dada pelo próprio documento norteador, de adaptar. A técnica [da SEDUC] pode até achar ruim, mas mostramos que conhecemos o documento, que sabemos o que estamos fazendo, que não começamos ontem. Antes dela, antes do Inovador, já fazíamos a qualidade da educação no Estado. E esse reconhecimento é geral: todo mundo reconhece nossa escola como boa. (Entrevistado 3 )

Sabendo, então, da força da escola no quadro geral educacional do Estado, os depoentes que, decerto, contribuem para seu sucesso vão expondo os enfrentamentos, as disputas para significação das políticas e do projeto de qualidade que consideram viável. Na verdade, mais do que hegemonizar um tipo de qualidade que, pelo histórico geral da escola, se daria pelo desempenho quantitativo dos seus alunos, docentes e o corpo gestor da escola Urbana buscam estabelecer um elo com a formação humanística, considerada como essencial para uma vida digna. Desse modo, tentam construir sentidos que caibam dentro dos limites de ação da própria instituição. Mesmo discordando, em tese, de uma formação tecnicista, é nela que encontram elementos para se manterem no jogo, nas disputas por significação que viabilizam as políticas.

Partilhando as ideias de Ball (1998), são nesses sentidos acima elencados que as escolas criam suas próprias políticas, aperfeiçoando e fixando aspectos das decisões políticas nacionais dentro de suas próprias culturas e práticas laborais. As escolhas, mas do que resultado de opções tomadas pelos sujeitos nas escolas, são negociações com os 
diversos movimentos em disputas, desde lutas que envolvem interesses da comunidade escolar e da categoria docente até tentativas de atendimento de diretrizes curriculares, como, por exemplo, o documento norteador do ProEMI. Desta forma, podemos perceber a negociação entre os macros e micros interesses, dando formatação a um tipo de política educacional (MAINARDES, 2006). Dizer isso significa, conforme o que foi lido em Ball, Maguire e Braun (2012) e Lopes e Macedo (2006), que vários elementos influenciam a realização da política.

Não é possível, portanto, estabelecer um padrão nacional para qualidade, como também, em nenhuma instância, política alguma pode ser implementada. Toda política é construção única da escola, de acordo com seus interesses, condições, disputas e resistências, resultando em produções híbridas. A ressignificação por hibridismo nas políticas de currículo, como apresenta Lopes (2005, 2006), em diálogo com Laclau (2003), e Tura (2009), fazem parte das lutas para a consolidação de um ideal de qualidade da educação que, por sua vez, passa pela solidificação de um ideal de formação humana. Sendo assim, há uma disputa totalmente interessada, envolvendo os complexos canais e desejos de grupos e indivíduos, alguns revelados, outros, impossíveis de se conhecer ou dimensionar.

Entendemos, pois, que, tanto quanto os números e aprovações são usados como qualificadores da escola Capital, o apego ao passado e aos "tempos gloriosos" funciona para manter a importância da escola Urbana. Logo, é na dinâmica do reconhecimento de singularidade que a proposta é "adequada à realidade" (entrevistado 3) ou "construída de acordo com os interesses e condições dos alunos" (entrevistado 4), pois, não adianta “colocar um projeto em tempo integral se a realidade de nosso aluno diz que ele não vem" (entrevistado 6).

De posse dessas falas, a readaptação das atividades do ProEMI, de acordo com nossa interpretação, é a construção da própria política. Isto é, não existe política como intenção ou discurso anterior, ela é construída na escola, mesclando discursos e dandoIhes sentidos que envolvem os fins da educação e os diversos interesses em disputas na realidade escolar, entendida como muito além do lugar, pois está relacionada contextualmente com o global. São nessas interações, portanto, que a política se realiza. 
Com efeito, a proposta do ProEMI é um texto e, como todo texto, está sujeito a infinitas leituras e releituras, reinterpretações e ressignificações, além de construções de sentidos a partir de contextos. Contextos que, vale reprisar, trazem elementos do local e do global, ultrapassando a compreensão imediata das estruturas, pois envolvem embates, lutas, interesses de diversos segmentos em busca de legitimar suas demandas (LOPES, 2006). Posto isso, não se desconsidera suas possibilidades de influenciar a política a ser realizada nos ambientes educacionais.

Por fim, reforçamos que o "reconhecimento" da escola, seja pela comunidade, seja pelos órgãos diretivos do estado, influencia decisivamente na forma como a política será efetivada na escola. Todavia, não estamos afirmando que há relação direta entre nível de reconhecimento e implementação das políticas na escola. Seguramente, discordamos da fórmula de Ball (1998), “mais poder, igual a menos implementação” e, no sentido oposto, "menos poder, igual a mais implementação". Assim, não acreditamos existir relação direta entre o grau de poder da escola com a aceitação ou não da política. O que articulamos é muito mais do que isso. Em outras palavras, nos dois casos aqui analisados existem forças e disputas em jogo, e em qualquer caso as políticas serão ressignificadas contextual e diferentemente em cada realidade.

Dessa maneira, mesmo sendo verdade que a escola Capital tem alguns trunfos para lidar com os órgãos diretivos, sendo capaz de interferir na forma como tais órgãos irão pensar e agir sobre a escola, o mesmo é lícito dizer sobre a escola Urbana, haja vista que, em ambas, as políticas são traduzidas contextualmente. 


\section{Referências}

BALL, Stephen. Education reform: acritical and post-structural approach. Buckingham: Open University Press, 1994.

BALL, Stephen. Cidadania global, consumo e política educacional. In: SILVA, L. H. da. A escola cidadã no contexto da globalização. Petrópolis: Vozes, 1998. p. 121-137.

BALL, Stephen; BOWE, Richard. El currículum nacional y su “puesta en práctica”: el papel de los departamentos de materias o asignaturas. Revista de Estudios del Currículum, v. 1, n. 2, p. 105-131, 1998.

BALL, Stephen; Mainardes, Jefferson. (Orgs.). Políticas educacionais: questões e dilemas. São Paulo: Cortez, 2011.

BALL, Stephen, MAGUIRE, Meg.; BRAUN, Annete. How schools do policy: policy enactments in secondary schools. Londres: Routlegde, 2012.

BUSNARDO, Flávia de Mattos Giovannini. Políticas curriculares para o ensino médio: a atuação da comunidade disciplinar de ensino de biologia. In: REUNIÃO ANUAL DA ANPED, 32, Caxambú, 2009. Anais... Caxambú: ANPED, 2009.

BRASIL. Ministério da Educação. Parâmetros curriculares nacionais do ensino médio. Brasília: MEC, 1999.

BRASIL. Ministério da Educação. Ensino médio integrado à educação profissional. Brasília: MEC, 2006.

CANDAU, Vera Maria. Qualidade da educação: um discurso inovador? Rio de Janeiro: Novamerica, 2002.

FREITAS, Dirce Nei Teixeira de. Avaliação da educação básica e ação normativa federal, Cadernos de Pesquisa, v. 34, n. 123, p. 663-689, set./dez., 2004.

HALBWACHS, Maurice. A memória coletiva. São Paulo: Centauro, 2006.

LACLAU, Ernesto. Power and representation. In: Poster, M. Politics, theory and contemporary culture. New York: Columbia University Press, p. 277-297, 2003.

LOPES, Alice Casimiro; MACEDO, Elizabeth. Teorias de currículo. São Paulo: Cortez, 2011. LOPES, Alice Casimiro. Discursos nas políticas de currículo. Currículo sem fronteiras, v.6, n.2, p. 33-52, jul./dez., 2006.

LOPES, Alice Casimiro. Política de currículo: recontextualização e hibridismo. Currículo Sem Fronteiras, v.5, n.2, p. 50-64, jul./dez., 2005. 
LOPES, Alice Casimiro; MACEDO, Elizabeth. Políticas de currículo em múltiplos contextos. São Paulo: Cortez, 2006.

MAINARDES, Jefferson. Abordagem do ciclo de políticas: uma contribuição para a análise de políticas educacionais. Educação e Sociedade, Campinas, v.27, n.94, p.47-69, jan./abr., 2006.

SANTOS, Jean Mac Cole Tavares; OLIVEIRA, Marcia Betania de. Políticas curriculares no ensino médio: ressignificações no contexto escolar. Currículo Sem Fronteiras, v. 13, n. 3, p. 497513, set./dez. 2013.

SANTOS, Jean Mac Cole Tavares. de novo ensino médio aos problemas de sempre:entre marasmos, apropriações e resistências escolares. Fortaleza: Edições UFC, 2007.

TURA, Maria de Lourdes. A recontextualização por hibridismo na prática pedagógica da disciplina Ciências. Currículo Sem Fronteiras, v. 9, p. 133-148, 2009.

Recebido em: 24/05/2014 Aprovado em: 04/08/2014

Universidade do Estado de Santa Catarina - UDESC Programa de Pós-Graduação em Educação - PPGE Revista Linhas Volume 17 - Número 33 - Ano 2016 revistalinhas@gmail.com 